\title{
Bicycle network performance: Assessing the directness of bicycle facilities through connectivity measures, a Montreal, Canada case study
}

\author{
Geneviève Boisjoly \\ Département des génies civil, géologique et des mines \\ Polytechnique Montréal \\ 2900 boul. Édouard-Montpetit \\ Montréal, Québec, H3T 1J4 \\ Canada \\ E-mail: gboisjoly@polymtl.ca
}

\author{
Ugo Lachapelle \\ Département d'études urbaines et touristiques, \\ École des sciences de la gestion, \\ Université du Québec à Montréal, \\ Case postale 8888, Succursale Centre-Ville, Montréal (Québec) H3C 3P8 \\ Montréal, QC, Canada \\ Phone: (514) 987-3000 x5141 \\ Fax: (514) 987-7827 \\ E-mail: lachapelle.ugo@uqam.ca
}

\author{
Ahmed El-Geneidy \\ School of Urban Planning \\ McGill University \\ Suite 400, 815 Sherbrooke St. W. \\ Montréal, Québec, H3A 2K6 \\ Canada \\ Tel.: 514-398-8741 \\ Fax: 514-398-8376 \\ E-mail: ahmed.elgeneidy@mcgill.ca
}

For Citation Please use: Boisjoly, G., Lachapelle, U., \& El-Geneidy, A. (In press). Are we connected? Assessing bicycle network performance through directness and connectivity measures, a Montreal, Canada case study. International Journal of Sustainable Transportation. 


\begin{abstract}
Over the last two decades, cycling has seen a rise in popularity in North American cities, which are continuously expanding their bicycle networks. While studies highlight that a good utilitarian bicycle network should provide direct routes for cyclists to reach their desired destinations, most network assessments simply measure the length and growth of bicycle facilities. This study evaluates the performance of the bicycle network in Montreal, Canada using a set of complementary indicators accounting for the directness of bicycle facilities between observed origins and destinations of cyclists. The study first uses data on routes taken by cyclists from an online survey conducted in Montreal in 2009 to derive a perceived reduced cost of travelling on bicycle facilities. By applying the derived cost reduction coefficient to bicycle facilities (0.77), bicycle routes are then predicted for 1482 cycling trips from the 2013 Montreal Origin-Destination survey. For each predicted route, the proportion of route on bicycle facilities and the diversion from the shortest path are calculated to assess the directness allowed by bicycle facilities. These two indicators are then used to measure network connectivity. The findings reveal that only $33 \%$ of the routes are connected with a diversion lower than $12 \%$ and a route proportion on facilities higher than $50 \%$. The results also highlight underperforming neighborhoods and demonstrate the importance of designing well-connected facilities between the boroughs. This study offers a proof of concept towards the development of a new methodology to measure bicycle network connectivity and support bicycle infrastructure planning.
\end{abstract}

Keywords: Bicycle network efficiency, Bicycle paths, Connectivity, Directness, Cycling routes, Travel behavior 


\section{INTRODUCTION}

Over the last three decades, cycling has seen a rise in popularity in North American and European cities (Pucher \& Buehler, 2017). Research shows that supplying bicycle facilities generally provides a positive experience for cyclists and is related to higher cycling rates and mode shares (Aultman-Haulm, Hall, \& Baetz, 1997; Damant-Sirois, Grimsrud, \& El-Geneidy, 2014; Sener, Eluru, \& Bhat, 2009; Snizek, Nielsen, \& Skov-Petersen, 2013). Accordingly, multiple cities in North America are focused on expanding their bicycle networks (Pucher, Buehler, \& Seinen, 2011) to offer an alternative to motorized commuting modes. While the length of bicycle facilities and its growth rate are used in many studies and planning documents to assess a city's network (Houston-Galveston Area Council, 2016; Vijayakumar \& Burda, 2015; Ville de Montréal, 2008, 2013b), these metrics indicate little about the efficiency of the network for accessing everyday destinations. An efficient bicycle network should allow cyclists to reach their desired destinations using bicycle-friendly routes on a large share of their trips, and without undue detours (Damant-Sirois et al., 2014; Dill, 2009; Mekuria, Furth, \& Nixon, 2012; Schoner \& Levinson, 2014). A lengthy but sinuous network along a river can be of great value for recreational purpose but impractical for commuting. Inversely, straight routes along busy boulevards can provide fast and direct connections, but raise concerns regarding safety and comfort of users. As there is often a trade-off between route directness and quality of route, multiple indicators are needed to assess overall bicycle network performance. However, other than length, very few quantitative indicators addressing overall network performance have been widely adopted to plan cycling networks (Lowry, Callister, Gresham, \& Moore, 2012; Pucher, Dill, \& Handy, 2010; Schoner \& Levinson, 2014).

The current study proposes a set of complementary indicators to assess the overall performance of bicycle networks based on cyclists' travel behavior and actual trip origins and destinations. More specifically, the study aims to offer a new approach to assess the directness of bicycle facilities between observed origins and destinations of cyclists using increasingly available data. To achieve this overarching research goal, two objectives are considered. The first objective seeks to analyze the travel behavior of cyclists in Montreal to derive a cost reduction coefficient for bicycle facilities and to empirically define 
thresholds that will be used in the second part of the analysis. The second objective aims to develop a set of performance indicators using a representative sample of cyclists' trip origins and destinations for which routes are predicted based on the derived cost reduction coefficient. A first indicator measures the route diversion (detour expressed in share of total trip distance) needed to use the bicycle network as compared with the shortest-path street network distance. A second indicator measures the proportion of a route travelled on bicycle facilities. These two indicators were selected because they reflect characteristics highly valued by cyclists (spending more time on cycling paths that provide a relatively direct route) and because they are easy to communicate and interpret. Building on these two complementary indicators, a third indicator, network connectivity is then assessed, using thresholds based on the reported behavior of cyclists in Montreal. Using these indicators on the Island of Montreal, Canada, this paper then spatially assesses the performance of the bicycle network in getting riders to where they want to go.

The study uses data from a large-scale online cycling behavior survey conducted during the summer of 2009 (Larsen \& El-Geneidy, 2011) and a regional origin destination (OD) travel survey conducted in 2013. The 2009 survey provides detailed information on reported bicycle trips including detailed route information, while the 2013 regional travel survey provides origins and destinations of a representative sample of cycling trips in 2013. Although the area of study is restricted to the Island of Montreal, this research provides methodological insight on how to assess the overall performance of cycling networks in addition to their size, using available data and resources. This study presents a proof of concept for the development of a methodology that can benefit transport engineers and planners around the world as they try to promote bicycle commuting by developing new bicycle facilities.

\section{LITERATURE REVIEW}

\section{Route Choice and Preferences of Cyclists}

Bicycle commuting is positively associated with the provision of off-street paths and on-street lanes, as they provide a better traveling experience for cyclists (Buehler \& Pucher, 2012; Snizek et al., 2013). More specifically, studies report that the presence of bicycle lanes, the low volume of motorized traffic and the 
suitability (e.g. comfort, topography) and safety of bicycle route are major attributes of an attractive bicycle network and of cyclists route choice (Broach, Dill, \& Gliebe, 2012; Buehler \& Dill, 2016; Casello \& Usyukov, 2014; Damant-Sirois et al., 2014; Dill, 2009; Ehrgott, Wang, Raith, \& van Houtte, 2012; Flügel, Ramjerdi, Veisten, Killi, \& Elvik, 2015; Handy \& Xing, 2011; Sener et al., 2009; Willis, Manaugh, \& El-Geneidy, 2015).

In addition to the physical characteristics of the paths they use, cyclists value route directness, high travel speed (Damant-Sirois et al., 2014; Ehrgott et al., 2012), low travel time and distance (Broach et al., 2012; Dill, 2009; Handy \& Xing, 2011; Hunt \& Abraham, 2007; Rietveld \& Daniel, 2004; Sener et al., 2009) and continuous bicycle infrastructure (Sener et al., 2009). As such, Schoner and Levinson (2014), in an assessment of 74 urban bicycle networks in the US, found a positive relation between directness and connectivity of cycling network routes, and bicycle commuting. In other words, winding paths and frequent stop-and-go disfavor utilitarian bicycling. Since cyclists value direct connections as well as safe and suitable routes that provide easy access, numerous studies have looked into how cyclists balance these criteria when choosing a route. Hunt and Abraham (2007) analyzed stated preferences regarding bicycle routes to a utilitarian destination and found that time spent in mixed traffic is 2.8 or 4.1 costlier to cyclists than time spent on bicycle paths (shared with pedestrians) or designated bicycle lanes, respectively. Accordingly, cyclists are willing to make detours to use bicycle facilities, which inversely, are less costly. In a study in Montreal, Larsen and El-Geneidy (2011) found that respondents who used bicycle facilities added an average of $2.2 \mathrm{~km}$ to their trips in terms of detours compared to non-path users. Part of this discrepancy can be explained by different trip purposes, where recreational cyclists can be expected to have less time restrictions, value paths more and may accordingly decide to take greater detours. Similarly, based on a stated preference survey, Tilahun, Levinson, and Krizek (2007) reported that cyclists would be willing to add up to 20 minutes to their trips in order to use an off-road bicycle trail instead of using an on-road lane lined with side parking.

Nevertheless, not all cyclists consider such detours; segmented analyses reveal that route choices and stated preferences differ based on types of cyclists. For example, Hunt and Abraham (2007) reported 
that cyclists with higher levels of comfort and experience in mixed traffic give lower cost value to time spent in mixed traffic. Broach et al. (2012) found that commuting cyclists value trip directness more than the presence of infrastructure, while recreational cyclists are more likely to use bicycle infrastructure, a finding supported elsewhere (Larsen \& El-Geneidy, 2011). A large amount of literature also explores the influence of different types of bicycle paths on cyclists (Broach et al., 2012; Larsen \& El-Geneidy, 2011; Mekuria et al., 2012; Tilahun et al., 2007). However, this is not the focus of the present study, as this data was not available for our analysis. Nonetheless, the method we propose can be adapted to this purpose.

\section{Bicycle Network Performance Assessment: Bicycle Facilities, Directness and Connectivity}

Based on the literature on the preferences of cyclists, a good utilitarian network should provide direct connections requiring minimal detours (Schoner \& Levinson, 2014) and enabling cyclists to spend a larger share of their trip on the cycling network. While most research on network efficiency has focused on transit and street networks (Lee, 2008; Lee, Choi, Yu, \& Choi, 2015; Levinson \& El-Geneidy, 2009), some recent studies have developed efficiency measures for bicycle networks. In this regard, Schoner and Levinson (2014) measured directness and connectivity of bicycle networks of 74 American cities. Connectivity was assessed through various indices of ratios between the numbers of edges (path or lane segments) and vertices (intersections or endpoints) of bicycle facilities. For example, a well-connected cycling network would be characterized by a high segment to intersection ratio. While this approach provides a rigorous way to measure network connectivity, it does not account for the location of actual origins and destinations of cyclists and the trips they are likely to take. Yet, an efficient and well-connected bicycle network should allow individuals to efficiently reach their desired destinations (Levinson \& El-Geneidy, 2009; Mekuria et al., 2012).

In this regard, Lowry et al. (2012) developed a method to measure the level of accessibility to destinations (commercial centers) by bicycle, using the Bicycle Level of Service (BLOS) to determine an impedance function. The BLOS is calculated following the Highway Capacity Manual 2010 equations, which considers several adjustment factors based on a variety of attributes such as width of bicycle lanes, 
proportion of occupied on-street parking, vehicle traffic volume and percentage of heavy vehicles. As highlighted in previous research (Wang, Palm, Chen, Vogt, \& Wang, 2016), such approach requires an extensive amount of data that is often not available to cities. As an alternative, Mekuria et al. (2012) measured 'low-stress connectivity' of bicycle networks in San José, California based on actual demand. The authors defined low-stress connectivity as the percentage of trips connected using bicycle-friendly routes and without excessive detours. Bicycle-friendly segments were defined based on the traffic stress imposed to cyclists. The Level of Traffic Stress (LTS) was defined for bicycle paths separated from traffic, bicycle lanes and streets with mixed traffic using a variety of factors such as street and/or lane width and speed limit or prevailing speed. Intersections were also assigned a LTS based on their configuration. The LTS were then benchmarked, from 1 to 4 , based on the Dutch bicycle facility planning and design standards. Regarding the excessive detour criteria, a threshold of $25 \%$ longer than the shortest path was used. This threshold was selected based on a previous study in Vancouver, Canada that found that $90 \%$ of non-recreational cyclists trips were within $25 \%$ of the shortest route distance (Winters, Teschke, Grant, Setton, \& Brauer, 2010). This approach provides a comprehensive measure of connectivity and is intuitively understandable for planners and can relate to users' experience. The method, however, also requires a significant amount of data from multiple sources as well as on-site measurements on the street and bicycle networks. This makes it difficult to implement in many municipalities and does not allow deriving a user and network specific threshold.

Given the mounting interest in improving cycling networks in North American cities, developing accessible quantitative assessment methods is essential in equipping planners and engineers with the necessary tools to design, assess and improve their network. The literature reveals that while multiple criteria need to be addressed when assessing bicycle network performance, very few overall performance indicators account for multiple factors. This study thus builds on network performance measures and bicycle route choice literature to offer easy-to-communicate indicators that are adapted to bicycle networks. The study spatially assesses the performance of the bicycle network using two complementary route-specific indicators (proportion of route on bicycle facilities and route diversion from shortest path) 
and one connectivity indicator aggregated spatially. The connectivity indicator is sensitive to cyclists' preferences, as it incorporates the proportion of the route on bicycle facilities as well as the route directness (diversion). The indicator is also sensitive to the local context as the cost reduction coefficient for bicycle facilities and the connectivity thresholds are obtained from actual cyclists' route choices in Montreal. While not all regions have access to survey data that incudes actual routes for bicycle trips, typical travel surveys can be used to complete part of the assessment. With the growing availability of Global Positioning System (GPS) route traces for trips, the methods proposed here will be replicable in a growing number of places.

\section{CASE STUDY DATA}

The area of study is the Island of Montreal, in Quebec, Canada, that comprises a population of 1,988,243 residents (Ville de Montréal, 2015) on an area of $499.1 \mathrm{~km}^{2}$ (Ville de Montréal, 2011). The agglomeration, an administrative entity encompassing the territory of the Island of Montreal (Figure 1), includes the 19 boroughs of the City of Montreal as well as 13 independent municipalities. For simplicity, in this study, we refer to these 32 entities as boroughs.

Montreal is often presented as a bicycling-friendly city in North America (Babin, 2015; Copenhagenize Design Company, 2015; Walker, 2014). In the last ten years, the Island of Montreal has experienced a rise in cycling's popularity, namely with the introduction of the BIXI bicycle-sharing system in 2009. The total length of bicycle facilities has increased continuously, from $400 \mathrm{~km}$ in 2009 to $602 \mathrm{~km}$ in 2013 and 748 km in 2015 (Vélo-Québec, 2015; Ville de Montréal, 2008, 2013b). Figure 1 illustrates the bicycle network on the Island of Montreal. In 2013, 2.5\% of the trips on the Island of Montreal were made by bicycle (Vélo-Québec, 2015). 


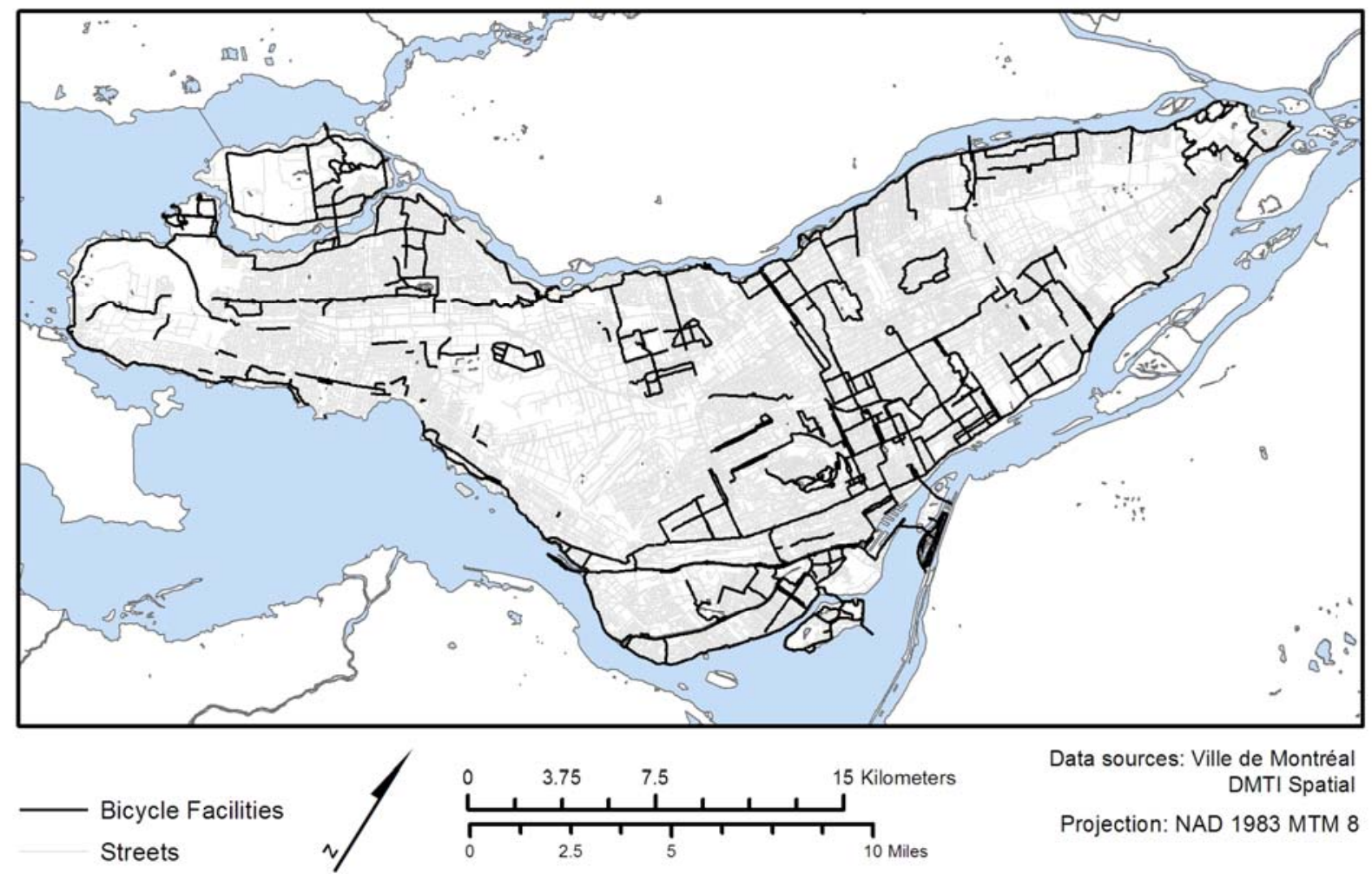

FIGURE 1 Bicycle and Street Networks on the Island of Montreal (2013)

\section{Route Choice of Cyclists in Montreal}

Data collected in a 2009 survey provides information on trips made by bicycle, using bicycle facilities or not (Larsen \& El-Geneidy, 2011). This online survey was heavily advertised through social media, in local newspapers, and at major cycling events through flyer distribution. The origin and the destination of the most recent home-based trip, and the locations where the cyclist got on and off the bicycle facility, if they used any, were collected as part of the survey. Only reported work and school trips are considered in the current study. The sample included 1525 respondents who cycled from home to work or school on the Island of Montreal. This dataset allows calculating the distance that each cyclist added to his or her trip in order to use a bicycle facility as compared with the shortest network path. We use this data to derive a cost reduction coefficient for cycling facilities. The dataset is also used to develop thresholds for the connectivity measures that will be developed later. Since the values generated here are context specific, we encourage other regions to deploy surveys or other data gathering that enable a region-specific validation of 
cycling facilities preferences.

\section{Origins and destinations of cyclists in 2013}

In order to assess the extent to which the bicycle network allows individuals to reach their desired destinations, actual and representative origin and destination locations must be used (Levinson \& El-Geneidy, 2009; Mekuria et al., 2012). Accordingly, the 2013 Origin-Destination Survey conducted by the Agence métropolitaine de transport de Montréal (AMT) is used to explore the performance of the cycling network (Agence Métropolitaine de Montréal (AMT), 2013). The OD survey samples around $4.35 \%$ of the households in each of the 113 municipal sectors of the Greater Montreal to ensure a representative spatial distribution, and households are selected through a random and systematic sampling process. This dataset provides origins and destinations for a representative sample of the cyclist population in 2013. Using this type of dataset, which is typically available in most large metropolitan areas in North America and Europe, provides a methodology that can be replicated elsewhere. The dataset contains detailed information on respondents' trips including trip origin and trip destination (XY coordinates), main transportation mode and purpose of the trips. From this database, home-based trips made by bicycle for work or school purposes were selected. Because the bicycle network is not available across the entire metropolitan region, we restricted the sample to bicycle trips originating and ending on the Island of Montreal ( $\mathrm{n}=1482)$.

Table 1 presents the summary statistics of each sample. Both samples exhibit similar distributions in terms of status and gender, although the 2013 OD survey has a slightly higher proportion of students and men. In terms of age, the 2013 OD survey captures greater age diversity, with cyclists ranging from 5 to 74 years old, and with a standard deviation of 14.77 (compared to 9.90 in the 2009 survey). The cyclists from the 2013 OD sample are on average older and have a higher proportion of car ownership. 
TABLE 1 Summary statistics of the two samples

\begin{tabular}{|l|c|c|c|c|c|c|c|c|c|c|}
\hline \multicolumn{1}{|c|}{2009 survey respondents } \\
\hline Variable & St. Dev & Min & Max & Average & Median & St. Dev & Min & Max & Average & Median \\
\hline Age & 9.90 & 18 & 70 & 33.98 & 31 & 14.77 & 5 & 74 & 36.39 & 36 \\
\hline $\begin{array}{l}\text { Car } \\
\text { ownership* }\end{array}$ & 0.66 & 0 & 4 & 0.56 & 0 & 0.76 & 0 & 4 & 0.90 & 1 \\
\hline \multicolumn{1}{|c|}{ Proportion of respondents } \\
\hline Status & \multicolumn{4}{|c|}{$\begin{array}{c}\text { Workers: } 74 \% \\
\text { Students: } 23 \% \\
\text { Other: } 3 \%\end{array}$} & \multicolumn{4}{c|}{ Proportion of respondents } \\
Sen: $58 \%$ \\
Gomen: $42 \%$
\end{tabular}

* Number of cars per household

\section{METHODOLOGY}

The overarching aim of this study is to generate performance measures based on actual travel demand and behavior. The first phase of the study seeks to analyze Montreal cyclists' route choice using the detailed cycling survey conducted in 2009. More specifically, we derive a cost reduction coefficient for bicycle facilities based on observed behavior. The reported behavior is also used to develop thresholds for the connectivity indicator developed in the second phase of the analysis.

The second phase of the study consists in predicting 1482 routes based on actual origins and destinations from the 2013 OD survey and using the derived cost reduction coefficient of cycling facilities from the 2009 survey. The study then generates performance measures for each predicted route (diversion and proportion on facilities) and a connectivity measure that aggregates the results spatially.

\section{Bicycle Network}

To analyze and generate bicycle routes using ArcGIS software, an appropriate street and bicycle network needs to be constructed. Since most cyclists do at least parts of their trip on the street network, it is necessary to generate a network that allows portions of routes to be on streets and other portions to be on existing bicycle facilities. Accordingly, we need to generate a network combining the bicycle facility network and the street network. The 2013 bicycle facility network was obtained through the open data website of the City of Montreal (Ville de Montréal, 2013a) and includes all types of bicycle facilities 
(on-street protected or painted cycling lanes and off-street dedicated paths). The street network used to generate the combined bicycle and street networks excludes streets on which cyclists cannot ride, such as highways. The two networks were then merged and linked.

Using ArcGIS network analyst, a level of preference can be assigned for bicycle facilities, which sets a lower cost coefficient for bicycle facilities (compared to streets) when calculating the shortest route. Put simply, the length of the bicycle facilities are multiplied by a cost-reduction coefficient. For example, a coefficient of 0.5 means that streets are two times more costly than bicycle facilities in terms of length. In other words, a bicycle facility of $1 \mathrm{~km}$ counts as traveling $0.5 \mathrm{~km}$. Given the lack of guidance in the literature on an appropriate cost reduction coefficient, identifying an average cost reduction coefficient based on observed travel patterns of cyclists is the first task of this paper.

\section{$\underline{\text { Route choice and cost reduction coefficient }}$}

In order to account for the average cyclists' preferences for cycling facilities (Larsen \& El-Geneidy, 2011; Mekuria et al., 2012), a cost reduction coefficient is derived using the 2009 survey. For each cyclist surveyed, a route is generated based on reported trip origin and destination, and reported access and egress points of the bicycle facility (named in survey by streets intersection), if one was used. If a cyclist used more than one facility in his trip, the cyclist was asked to report the details of the facility he or she used for the longest distance (referred to as the main facility). The following distances were then calculated: the actual distance travelled on the bicycle facility, the actual home to cycling facility access distance, the actual egress distance from bicycle facility to destination and the GIS-estimated shortest path (the most direct path from origin to destination on any street or facility that can be used by a cyclist).

It is assumed that a cyclist will decide to use a bicycle facility if the overall perceived cost of the resulting route is lower that the perceived cost of the shortest path. The perceived costs can be expressed as a function of the length (equations 1 and 2):

$$
\begin{gathered}
P_{\text {bicycle facility }}=R * L_{\text {bicycle facility }} \\
P_{\text {street }}=L_{\text {street }}
\end{gathered}
$$


Where $P$ represents the perceived cost (in meters), $L$ the length (in meters), and $R$ the cost reduction coefficient for bicycle facilities. For a cyclist to use a bicycle facility, the perceived cost of their entire route has to be lower than the perceived cost of the shortest path (equation 3). The perceived cost of the route is divided in two perceived cost components: the perceived cost of the bicycle facility, and the perceived costs of the route travelled on the streets (equation 4). Equation 5 then expresses the costs of each segment in terms of distance, where the distance travelled on the street is equal to the sum of the access and egress distances.

$$
\begin{gathered}
P_{\text {route }}<P_{\text {shortest path }} \\
P_{\text {bicycle facility }}+P_{\text {street }}<P_{\text {shortest path }} \\
R * L_{\text {bicycle facility }}+\left(L_{\text {access }}+L_{\text {egress }}\right)<L_{\text {shortest path }}
\end{gathered}
$$

Isolating $R$, the cost reduction coefficient, we obtain the following equation (6):

$$
R<\frac{L_{\text {shortest path }}-\left(L_{\text {access }}+L_{\text {egress }}\right)}{L_{\text {bicycle facility }}}
$$

Using this formula (equation 6), we can calculate the higher limit of the perceived cost reduction for each cyclist who diverted from the shortest path. This higher limit can thus be considered a conservative estimate of cycling path value. The cost reduction coefficient is typically a value between 0 and 1 , where a value close to 1 means that the perceived cost of the bicycle facilities is similar to the perceived cost of streets. In contrast, a cost reduction coefficient close to 0 means that the perceived cost of the bicycle facilities is much lower compared to streets. Values close to zero indicate a strong preference for cycling paths, even if it means making a considerable detour. Each trip will yield a distinct preference value and thus a perceived cost reduction coefficient. In this study, we use the average value and apply it to cycling facilities.

\section{Bicycle Network Performance Indicators}

Using the average derived cost reduction coefficient and the bicycle and streets network, predicted routes are generated for each pair of origins and destinations of cyclists from the 2013 OD survey (see Figure 2 
and Table 2 as an example). In doing so, we assume that the 2013 respondents have similar preferences to the 2009 cyclists surveyed. Using the merged bicycle and street network described above, the predicted routes are calculated with the ArcGIS network analyst, which calculates the lowest cost (distance) route between an origin and a destination, while considering the cost reduction coefficient assigned to the bicycle facilities. For each predicted route, two performance indicators are calculated: route diversion from shortest path and proportion of route on bicycle facilities. Diversion, commonly used in the literature (Lee et al., 2015; Mekuria et al., 2012), is calculated by dividing the detour traveled (shortest path subtracted from total trip length) by the shortest path and multiplying by 100 . The proportion of the route on bicycle facilities is calculated using length on facilities as a share of total trip length. The distance of the route on bicycle facilities is calculated through GIS network software, by intersecting the actual route with the bicycle network. Note that routes shorter than $500 \mathrm{~m}$ were excluded from the analysis.

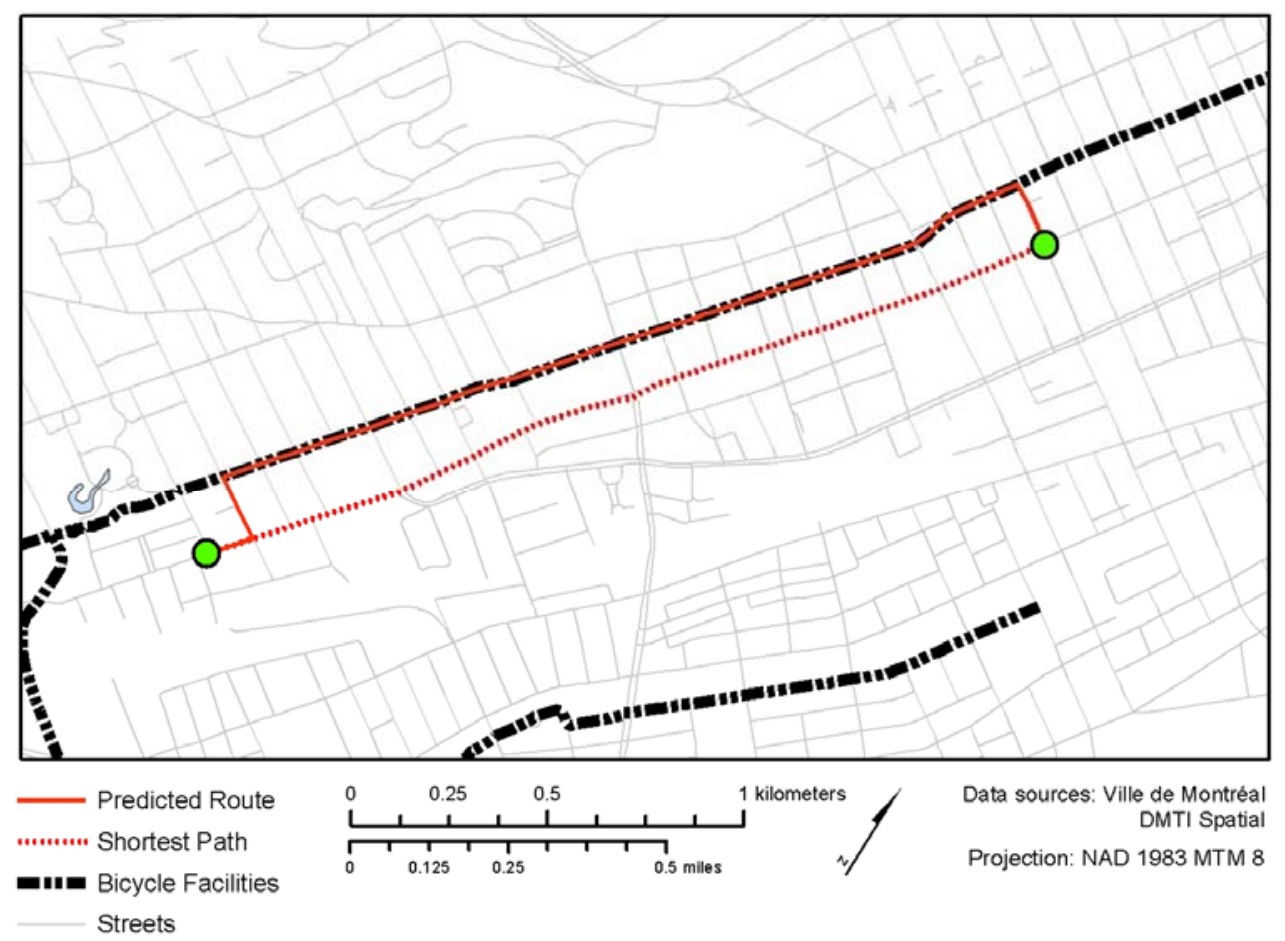

FIGURE 2 Shortest path and predicted Route (Example from 2013 OD survey) 
TABLE 2 Route characteristics and derived measures (Example from the 2013 OD survey)

\begin{tabular}{|l|c|}
\hline A. Distance Shortest Path (m) & 2,240 \\
\hline B. Distance Predicted Route (m) & 2,607 \\
\hline C. Detour (m) = B-A & 366 \\
\hline D. Diversion (\%) $=100^{*} \mathrm{C} / \mathrm{A}$ & 16 \\
\hline E. Distance on cycling facilities (m) & 2,162 \\
\hline F. Percentage of route distance on bicycle facilities $(\%)=100^{*} \mathrm{E} / \mathrm{B}$ & 83 \\
\hline
\end{tabular}

Since there is an inherent trade-off between route diversion and the proportion of the route travelled on bicycle facilities (a long diversion may not be worth the short distance that will be traveled on the cycling facility), it is necessary to assess these two indicators simultaneously. A measure of connectivity is generated, as it allows incorporating multiple criteria into one indicator. Mekuria et al. (2012) define a low-stress connectivity as the number of routes within an area that are connected (as a percentage of the total number of routes) based on two criteria: level of stress and diversion. Our connectivity measure is inspired from Mekuria et al. (2012) in the sense that we use a set of predefined criteria and empirically derived thresholds to determine whether a route is connected. As done by Mekuria et al. (2012), we use route diversion as a first criterion. We, however, replace their level of stress criteria with the proportion of route on bicycle facilities; a criterion that focuses on the time spent on the bicycle facilities rather than its quality. In sum, routes travelling a minimum proportion on bicycle facilities without exceeding a maximum detour are accordingly considered connected in our study. The area connectivity is, therefore, calculated as follows:

$$
\begin{gathered}
C_{k}=\frac{\sum_{i=1}^{n} C_{i, k}}{n} \\
C_{i, k}=\left\{\begin{array}{l}
1 \text { if } D_{i, k} \leq t_{D} \text { AND } F_{i, k} \geq t_{F} \\
0 \text { if } D_{i, k}>t_{D} \text { OR } F_{i, k}<t_{F}
\end{array}\right.
\end{gathered}
$$

Where $C_{k}$ is the network connectivity of area $k$ (in our case, borough) expressed as a proportion, 
$C_{i, k}$ is a binary function defining if the route between the home and work/school locations of cycling OD pairs $i$ beginning in area $k$ is connected, $n$ is the number of OD pairs, $D_{i, k}$ is the route diversion, $F_{i, k}$ the proportion of the route on a bicycle facilities, and $t_{D}$ and $t_{F}$ are the thresholds for route diversion and proportion of the route along bicycle facilities respectively. The maximum threshold for diversion and the minimum threshold for proportion of route along facilities are set based on averages of cyclists' observed preferences, obtained through the 2009 survey data. The average values were selected to benchmark the performance of the network in Montreal. Higher thresholds could be used in cities with more extensive bicycle networks, ideally with empirical identification of thresholds. Furthermore, depending on the planning or research objectives, and on availability of alternative data, different thresholds can be specified.

The connectivity of a route $\left(C_{i, k}\right)$ is null if at least one of the two criteria (proportion on bicycle facilities above threshold and diversion below threshold) is not met. Conversely, route connectivity is equal to one when the route meets the two criteria. This entails that some portions of a "connected route" may be travelled on streets without bicycle facilities. In doing so, the connectivity indicator specifically assesses the contribution of the bicycle facilities to reach destinations, regardless of the conditions of the on-street portion of the route.

\section{$\underline{\text { Performance analysis }}$}

We first generate these measures for the whole Island of Montreal and then specifically for each borough to conduct a spatial analysis of performance disparities across the Island of Montreal. Routes are assigned to boroughs based on their origins. In other words, all routes originating in a borough are considered when calculating the indicators of the borough. Only boroughs with 20 or more observations are included in the analysis to ensure a reasonable sample size. For each borough, the average diversion and proportion of trip on bicycle facilities and borough connectivity are calculated.

\section{Limitations}

Given the data available, some limitations must be considered. First, driving directions of the streets and bicycle facilities are not included in the network, as they were not provided in the original files. As a result, network distances might be underestimated, allowing routes to use all segments in both directions. Since 
both bicycle facilities and streets are considered two-way, diversion measures should not be significantly affected by this limitation.

Second, the type of bicycle facilities is not considered in this study as the data was not directly available. Similarly, street characteristics such as traffic volume, speed and slope were not considered. While such considerations are known to influence travel behavior and preferences, this study focuses on the presence of bicycle facilities compared to the absence of such facilities, thereby capturing the possibility to cycle on dedicated infrastructures rather than cycling with mixed traffic. The presence of bicycle facilities, which is shown to be a major determinant of route choice (Casello \& Usyukov, 2014), was selected as the variable of interest to reflect the directness of the bicycle network in linking origins and destinations. The single cost reduction coefficient derived in this study by averaging several observed trips represents the overall preference for bicycle facilities compared to streets, regardless of their characteristics. In doing so, the study focuses on offering a new methodology to predict route choice based on the presence of infrastructures, using commonly available data. Whereas assessing the specific characteristics of the routes and alternative paths falls outside the scope of this study, further studies could build on our methodology to develop a cost reduction coefficient for each type of bicycle facility, while accounting for various street attributes. Similarly, further studies could also investigate whether different trip lengths yield different cost reduction coefficient. For example, it is likely that individuals will be more willing to make detours on shorter trips.

Third, the data and method used to derive a cost reduction coefficient for bicycle facilities presents some limitations. Since only the main facility that was used is considered, it is assumed that the bicycle facility access and egress distances are travelled on streets. This might lead to under or overestimations of the cost reduction coefficients, especially in central boroughs, which are characterized by many small, interrupted bicycle facilities. Nevertheless, this study presents a simple method to derive a cost coefficient value based on a comparison between observed behaviors and shortest travel paths. With the growing availability of GPS tracking data, future studies could build on this method to derive more accurate and locally representative cost reduction coefficients for specific paths. 


\section{RESULTS}

\section{Route Choice of Cyclists and Derived Cost Reduction Coefficient from the 2009 Survey}

The route characteristics of cyclists surveyed in 2009 were calculated to derive a cost reduction coefficient and obtain threshold values for the connectivity indicator that will be calculated in the second part of this analysis. Out of the 1525 cyclists surveyed, 1093 (72\%) cyclists diverted from the shortest path to use a bicycle facility (Table 3). For these cyclists, an average diversion of $12 \%$ was observed, with on average $50 \%$ of the trips being made on bicycle facilities. Interestingly, in a study of 166 cyclists in Portland, Oregon, US using GPS tracking data, Dill (2009) finds similar results, where cyclists travel on average 49\% (all travel) or $52 \%$ (utilitarian travel) of their trip on bicycle infrastructure. In our study, however, $28 \%$ of the cyclists did not divert from the shortest path. Unsurprisingly, these cyclists travelled a lower proportion of their trip on bicycle facilities, on average $15 \%$. This suggests that these cyclists did not consider the presence of bicycle facilities in their route choice, either due the lack of facilities around their home and work/school, because the detour was not worth the comfort gain (most direct path on quiet streets for example), or because they equally value streets and bicycle facilities. In the first case, their travel behavior does not tell much about their preference for bicycle facilities. In the last case, the equal valuation of street and bicycle facilities is only representative of a small fraction of the cyclist population. As highlighted in multiple studies, cyclists that are comfortable riding in traffic and do not value bicycle facilities, referred to as 'dedicated cyclists' or 'fearless and strong' for example, represent a small share of the cyclists population (Damant-Sirois et al., 2014; Geller, 2006; Mekuria et al., 2012). Furthermore, in both cases, it is not possible to calculate a cost reduction coefficient since the length travelled on bicycle facilities is null (see equation 6). Accordingly, the cyclists that did not divert from the shortest path are excluded from our analysis. 
TABLE 3 Route characteristics of 2009 surveyed cyclists

\begin{tabular}{|l|c|c|}
\hline Route Characteristic and Indicator (Means) & $\begin{array}{c}\text { Diverting cyclists } \\
(\mathbf{n = 1 0 9 3})\end{array}$ & $\begin{array}{c}\text { Non-diverting cyclists } \\
(\mathbf{n}=\mathbf{4 3 2})\end{array}$ \\
\hline Length - Shortest path $(\mathrm{km})$ & 5.76 & 5.02 \\
\hline Length - Actual route $(\mathrm{km})$ & 6.46 & 5.02 \\
\hline Detour $(\mathrm{m})$ & 695 & 0 \\
\hline Diversion $(\%)$ & 12 & 0 \\
\hline Proportion of route on facilities $(\%)$ & 50 & 15 \\
\hline
\end{tabular}

The route choice of the cyclists surveyed in 2009 is used to derive an average cost reduction coefficient for bicycle facilities. For each cyclist diverting to use a facility, a coefficient is calculated based on the actual distance travelled on bicycle facilities, the access and egress distances, and the shortest path (see equation 6). Figure 3 represents the distribution of the cost reduction coefficient obtained for each cyclist. The values range from 0 to 1 , with the majority of the observations being closer to one. It is important to note that eight observations led to a negative preference value. Those observations were excluded as they were considered to be outliers: those values occurred for cyclists who made a large detour to spend a small distance on bicycle facilities (the sum of access and egress distances were greater than the shortest path). This could likely be associated to 1) utilitarian trips that are combined with leisure trips, 2) trip chaining that required an unreported stop, or 3) situations where access and egress distances are in fact travelled on bicycle facilities. After excluding the outliers, we obtain an average coefficient of 0.77 (median $=0.83$ ). This suggests that the average cyclist values bicycle facilities at least 1.30 times $(1 / 0.77=1.30)$ more than streets with no facilities. This value, although lower, is consistent with the findings of Hunt and Abraham (2007), who found that time spent in mixed traffic is 4.1 and 2.8 times more onerous than time spent on bicycle facilities (segregated bicycle paths and bicycle lanes respectively). The method used by Hunt \& Abraham (2007), stated preference instead of observed behavior, likely contributes to a higher preference values. Furthermore, the cost reduction coefficient calculated in this study represents the higher limit of the coefficient, and thus likely underestimates the actual preference value. Also, whereas Hunt \& Abraham (2007) directly average the preference values (values above 1), we average the cost reduction coefficient (values between 0 and 1). This partly explains discrepancies in the results, as averaging the reduction 
coefficients gives less weight to extreme values. To illustrate this situation, we use a simple example with two observations: cost reduction coefficient of 0.10 (preference value of 10) and cost reduction coefficient of 0.50 (preference value of 2). Averaging the cost reduction coefficient values, we obtain an average of 0.30 , which corresponds to a preference value of 3.33. Conversely, averaging the preference values ( 10 and 2 ), we obtain an average preference value of 6 . Finally, the study was conducted in a different context (Edmonton, Canada), which could partly explain the observed disparity. This suggests the need to compare experiments on observed behaviors in multiple places and to develop context-specific cost reduction coefficients.

\section{Distribution of coefficient}

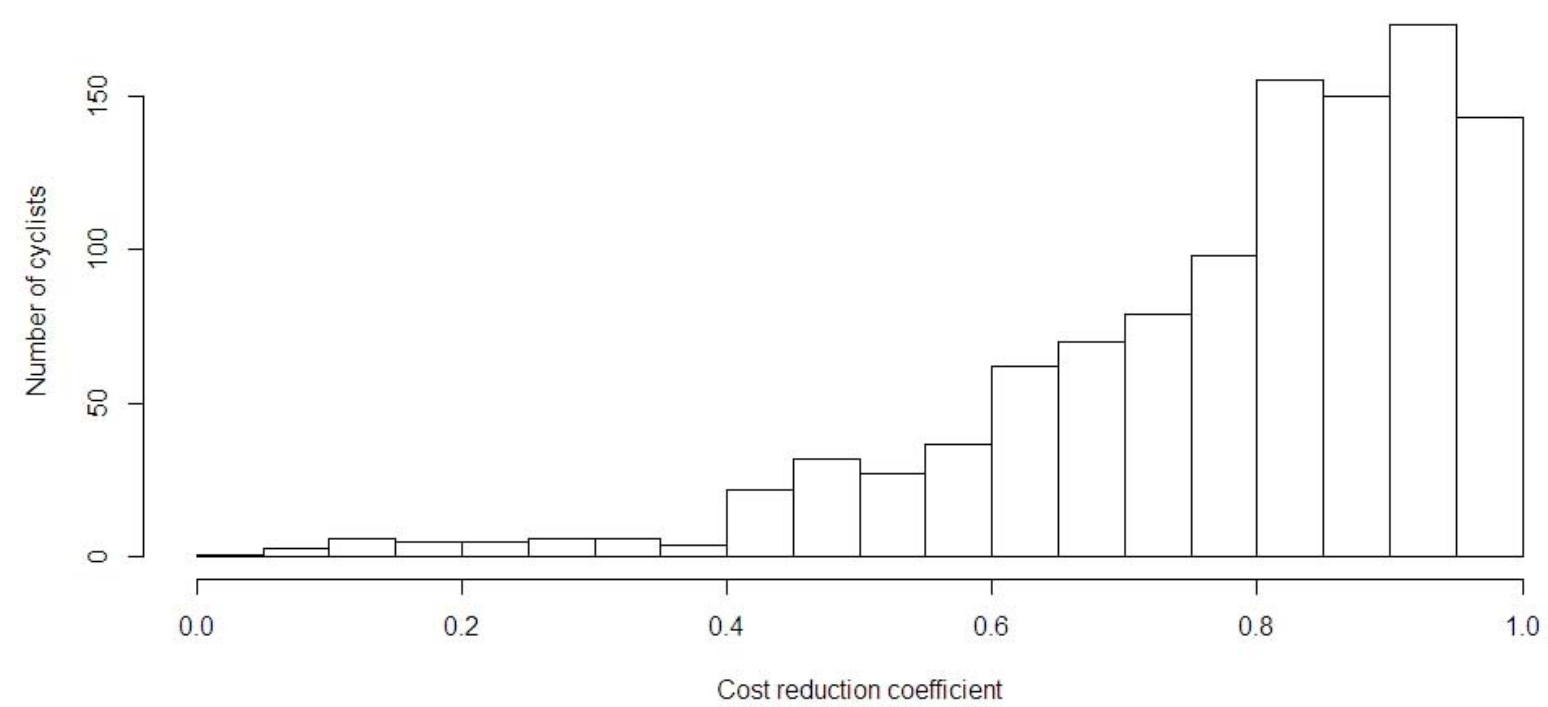

FIGURE 3 Frequency of the derived cost reduction coefficient for bicycle facilities (survey 2009) Performance of the Bicycle Network for 2013 - OD Cyclists' Trips

Using the cost reduction coefficient (0.77) applied to cycling facilities and the threshold values of diversion and proportion of route on facilities obtained in the previous section, this section assesses the performance of the 2013 bicycle network for the whole Island of Montreal using origins and destinations of cycling trips from the 2013 Origin-Destination survey. For comparison purposes, routes are generated with and without the 0.77 cost reduction coefficient of cycling facilities for the 1482 OD pairs. Table 4 presents the average route characteristics and performance indicators of the predicted routes, together with the connectivity of 
the network and the percentage of routes that use a bicycle facility. The results show that, if bicycle facilities are valued the same as streets (which means that no detour is being made), only $18 \%$ of the routes, in average, are travelled on bicycle facilities. This is, however, not reflective of many cyclists' behavior, which are generally willing to do small detours to reach bicycle facilities. As presented in Table 4, when reducing the perceived travel distance on cycling paths (by applying the coefficient), cyclists would spend on average $58 \%$ of their trip on a bicycle facility requiring a small detour (on average $4 \%$ ). Note that this $58 \%$ average is largely determined by observations from four boroughs that represent 822 of the 1482 observations. It is also important to note that the $4 \%$ average diversion is lower than the average $12 \%$ diversion observed for cyclists surveyed in 2009. This can be explained by two reasons. Firstly, the average diversion of $12 \%$ is raised by a limited number of cyclists that do large diversions (the median is only $8 \%$ ). Secondly, the software generates the route with the lowest perceived cost. When the perceived costs of the route with diversion (accounting for the 0.77 cost reduction coefficient for bicycle facilities) is lower than the most direct path, the former is selected. However, in many cases, the lowest-cost route is largely inferior to the most direct path, meaning that the diverted route does not require the maximum diversion that cyclists would be willing to do. In other words, it is possible to select the lowest-cost route without having to do a detour of $12 \%$. For example, if the shortest path were $1000 \mathrm{~m}$ long, a route with $522 \mathrm{~m}$ on bicycle facilities and $598 \mathrm{~m}$ on streets would be selected over the shortest path $(0.77 * 522 \mathrm{~m}+598 \mathrm{~m}=999.9 \mathrm{~m}$ and is accordingly lower than $1000 \mathrm{~m}$ - see equation 5) and would correspond to a diversion of $12 \%$. However, it is possible that the network allows a lowest-cost route with $522 \mathrm{~m}$ on bicycle facilities, and $500 \mathrm{~m}$ on streets. This would result in a perceived cost of $901 \mathrm{~m}$, which is lower than the $1000 \mathrm{~m}$ shortest path, and would only require a diversion of $2 \%$. In other words, a higher diversion would be observed if the lowest perceived cost route would for each route be just slightly below the shortest path. Also, in some cases, no detour is required to use bicycle facilities, which lowers the average detour.

With respect to the connectivity indicator, the results demonstrate that only $33 \%$ of the routes are connected with a diversion lower than $12 \%$ and a proportion on facilities higher than $50 \%$. The connectivity is much lower when the travel preferences of cyclists are not accounted for $(10 \%)$. Overall, these results 
demonstrate the low performance of the bicycle network in Montreal in allowing cyclists to reach their destinations using bicycle facilities, without undue detour. Furthermore, we observe that, using the cost reduction coefficient derived in the first part of the study, $90 \%$ of the predicted routes use a bicycle facility and users spend on average $58 \%$ of the trip on the facility. In contrast, only $32 \%$ of the predicted routes use a bicycle facility when no cost reduction coefficient is applied, and users spend on average $18 \%$ of the trip on the facility. These results highlight the need to consider route preferences of cyclists when assessing the performance of the network. It also suggests the importance of attributing a cost reduction coefficient to bicycle facilities when estimating trip routes.

TABLE 4 Mean route characteristics for 2013 OD survey cyclists' commute trips $(n=1482)$ using the lowest cost function

\begin{tabular}{|c|c|c|c|c|}
\hline & \multicolumn{2}{|c|}{$\begin{array}{l}\text { Road Network without } \\
\text { highways and with equally } \\
\text { valued cycling facilities }\end{array}$} & \multicolumn{2}{|c|}{$\begin{array}{l}\text { Road Network without highways } \\
\text { and with cycling facilities with cost } \\
\text { reduction coefficient }(0.77)\end{array}$} \\
\hline \multicolumn{5}{|c|}{ Route-level characteristics and indicators } \\
\hline & Mean (SD) & Min-Max & Mean (SD) & Min-Max \\
\hline Distance - Shortest path (m) & $4,383(3,449)$ & $502-30,678$ & $4,383(3,449)$ & $502-30,678$ \\
\hline Distance - Predicted route $(\mathrm{m})$ & - & - & $4,656(3629)$ & $503-31,444$ \\
\hline Detour $(\mathrm{m})$ & 0 & 0 & $219(273)$ & $0-2,406$ \\
\hline Diversion $(\%)$ & 0 & 0 & $4(3.8)$ & $0-19$ \\
\hline Proportion of route on facilities $(\%)$ & $18(20)$ & $0-100$ & $58(30)$ & $0-100$ \\
\hline \multicolumn{5}{|c|}{ Aggregated characteristics and indicators } \\
\hline Connectivity $(\%)$ & \multicolumn{2}{|c|}{$10 \%$} & \multicolumn{2}{|l|}{$33 \%$} \\
\hline $\begin{array}{l}\text { Percentage of routes that use a } \\
\text { bicycle facility }(\%)\end{array}$ & \multicolumn{2}{|l|}{$32 \%$} & \multicolumn{2}{|l|}{$90 \%$} \\
\hline
\end{tabular}

\section{$\underline{\text { Spatial analysis across boroughs }}$}

Grouping these results spatially provides information on variations across the region and can help identify areas that are underperforming regarding the directness of bicycle facilities between observed origins and destinations of cyclists. Figure 4 summarizes the average proportion of route on facilities and average diversion, by borough. The average proportion of routes on bicycle facilities varies from $32 \%$ to $65 \%$, and the average diversion varies from $2 \%$ to $5 \%$. Not surprisingly, we see a trade-off between the two indicators: boroughs with a lower average proportion of route on facilities typically have a lower average 
diversion. Where multiple facilities are available, cyclists will do longer detours to reach facilities along the way and travel greater distance on them. In contrast, when few facilities are available, cyclists will do shorter detours, but will also travel proportionally shorter distances on bicycle facilities. In some cases, no facilities are used, suggesting that facilities could not be reached without undue detour, based on the derived cost reduction coefficient. In this regard, the percentage of routes that do not use a bicycle facility ranges from $4 \%$ to $18 \%$ across boroughs, and is generally higher in boroughs with low diversion rates. However, when excluding routes that do not pass through bicycle facilities, the results observed in Figure 4 remain consistent.

The trade-off observed between the two indicators presented in Figure 4 illustrates the need to look at both indicators jointly to assess the performance of the bicycle network. Figure 5 presents the connectivity results, by borough, which considers both the proportion of route travelled on facilities and the diversion from shortest path. The darker red bars represent the percentage of routes that are connected based on the thresholds derived from the 2009 survey (12\% diversion, 50\% proportion on facilities). While Mekuria et al. (2012) use a 25\% diversion threshold, our study finds that cyclists divert by $12 \%$ in average to use bicycle facilities, which we use here to better reflect Montreal cyclists' behavior. A second connectivity indicator, based on a $12 \%$ diversion and $80 \%$ proportion on facilities is presented in Figure 5 (light red) to illustrate how stricter thresholds yield much lower results. For comparison purposes, the findings are presented in the same order as in Figure 4.

Commencing with our main connectivity indicator based on observed behavior thresholds (dark red), we observe that, overall, boroughs where a high proportion of the routes are travelled on facilities also tend to exhibit a higher connectivity. However, the average diversion of predicted routes starting from the borough influences the connectivity results. This highlights the importance of considering both indicators simultaneously. For example, Verdun scores higher than CDN-NDG and Villeray-Saint-Michel-Parc-Extension in terms of connectivity, although they have similar scores in terms of proportion on facilities. In contrast, Ville-Marie scores lower than Sud-Ouest and Mercier-Hochelaga-Maisonneuve, which have similar scores in terms of proportion of route on facilities. 
The connectivity indicator thus reflects the joint performance in terms of proportion of route on facilities and diversion. The connectivity results highlight boroughs in need of improvements, namely Mont-Royal, Saint-Laurent and Ahuntsic-Cartierville. In contrast, the boroughs of Rosemont-La Petite-Patrie, Plateau-Mont-Royal, Mercier-Hochelaga-Maisonneuve and Verdun are characterized by a high connectivity performance.

While the $50 \%$ thresholds for proportion of routes on facilities was set based on cyclists' behavior, it nevertheless represents a low performance of the bicycle network. We present an arbitrarily-set ideal situation for connectivity with an $80 \%$ threshold for proportion of route on facilities (Figure 5, light red) to assess how boroughs would fare. Using such threshold, no borough has connectivity levels above $40 \%$. As such, in every borough, fewer than $40 \%$ of the routes can be travelled with a large share on bicycle facilities (80\%), and without undue diversion (12\%). Looking at the relative performance of the boroughs depending on the set thresholds, the trend is similar although some discrepancies in how well boroughs do relative to others can be observed. Wide differences in Verdun and Outremont are likely explained by the relatively low number of observations (46 and 28 respectively). This suggests that the choice of connectivity thresholds and the number of observations can influence the results, and further research is needed to assess the effect of different thresholds and sample sizes. 


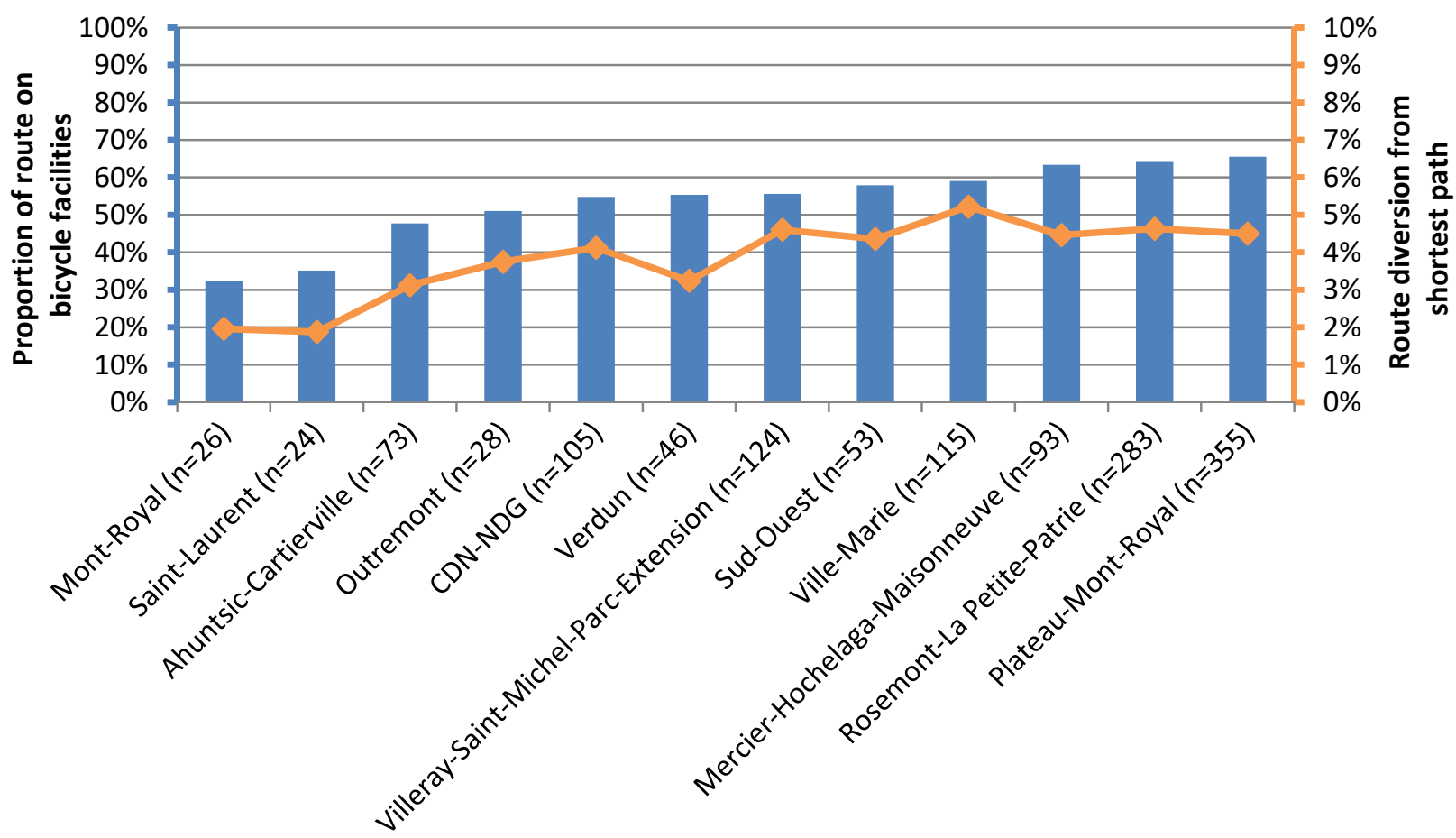

FIGURE 4 Average proportion of route on facilities and average route diversion from shortest path, based on origin of route

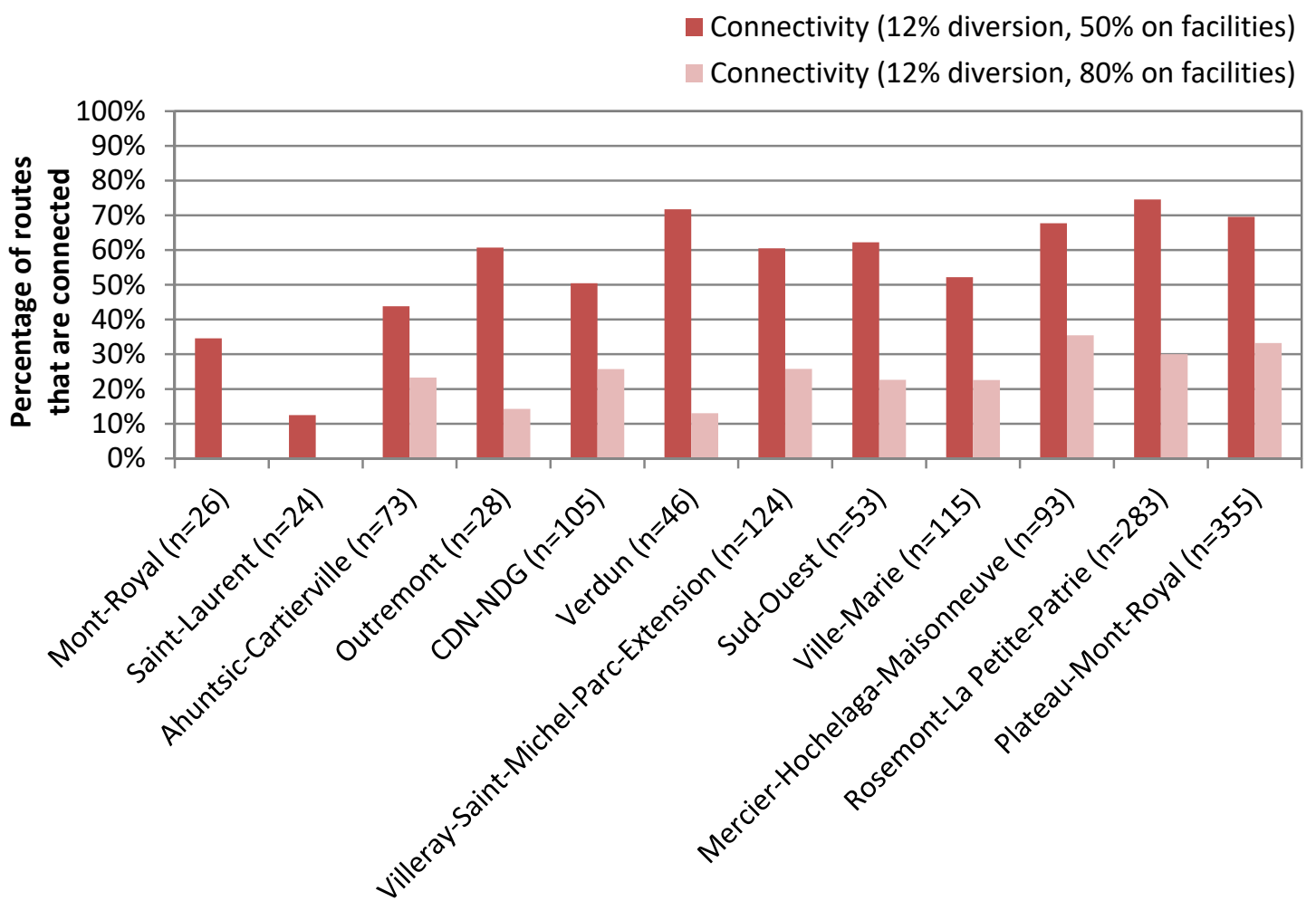

FIGURE 5 Connectivity indicator by borough using different thresholds, based on origin of route 
To understand how the presence of bicycle facilities and the design of the bicycle network influence the performance of the boroughs, we illustrate the findings spatially, together with the bicycle network. Figure 6 illustrates the connectivity results, which account simultaneously for proportion of route on facilities and route diversion from shortest path. The thresholds used in producing the connectivity indicator represent the travel behavior of 2009 cyclists: the proportion of routes that are characterized by at least $50 \%$ of their distance travelled on bicycle facilities with a diversion below $12 \%$. On one hand, the results suggest that boroughs that score the highest in terms of proportion on facilities (above 63\%) typically have a high density of facilities as well as multiple interconnected facilities in both axes (north-south and east-west). They also appear to be well connected to other boroughs by bicycle facilities. It is important to note that the Mercier-Hochelaga-Maisonneuve borough (\#11), although characterized by a lower density of facilities, scores high in terms of connectivity. This is likely explained by the fact that the population is concentrated in the southern part of the borough (where most trips are probably originating), which is better served in terms of bicycle facilities. This result highlights the need to consider demand when assessing the performance of a bicycle network. On the other hand, the boroughs that score low in terms of connectivity (below $44 \%$ ) have a lower density of bicycle facilities, and are not well connected to the surrounding boroughs. The rest of the boroughs (between 45 and 62\%) although served by multiple bicycle facilities, are characterized by fewer connections with surrounding boroughs. These results highlight the importance of having bicycle facilities that connect each borough to the surrounding boroughs. In light of these findings, a city-wide planning and design should be considered to ensure an integrated and interconnected network.

Overall, the results highlight the boroughs that have the lowest performance regarding their bicycle network. This analysis allowed identifying key features of the bicycle network that contribute to higher connectivity, namely the density of bicycle facilities, but also the links with the surrounding boroughs. It also allows assessing the performance of the bicycle network, in relation to the demand. From an equality perspective, transport planning should aim at removing obstacles in the cycling (and walking) networks, while developing infrastructures that provide adequate accessibility and safety for active modes 
(Mullen, Tight, Whiteing, \& Jopson, 2014). The methodology presented here can therefore be applied to equality studies by identifying gaps in the cycling network. An important note on this, however, is that the cycling trips, which have been used to reflect the demand for cycling facilities, might be induced by the presence of well-connected bicycle infrastructures. Conversely, individuals that wish to cycle, but avoid doing so given the lack of facilities connecting them to their destinations, are not considered in the current assessment. Further studies should thus consider assessing the demand for cycling trips based on other factors, such as population density, residential location of all mode-users and socio-demographic factors, to include all potential cycling trips. Other trip purposes could also be considered. Furthermore, to account for social equity considerations (Pereira, Schwanen, \& Banister, 2016), the methodology could be applied to develop a cost reduction coefficient specific to population groups identified as more vulnerable and subsequently conduct a segmented analysis. Further studies could build on the approach presented in this study to conduct segmented analyses and derive performance measures that are specific to different groups of cyclists. 


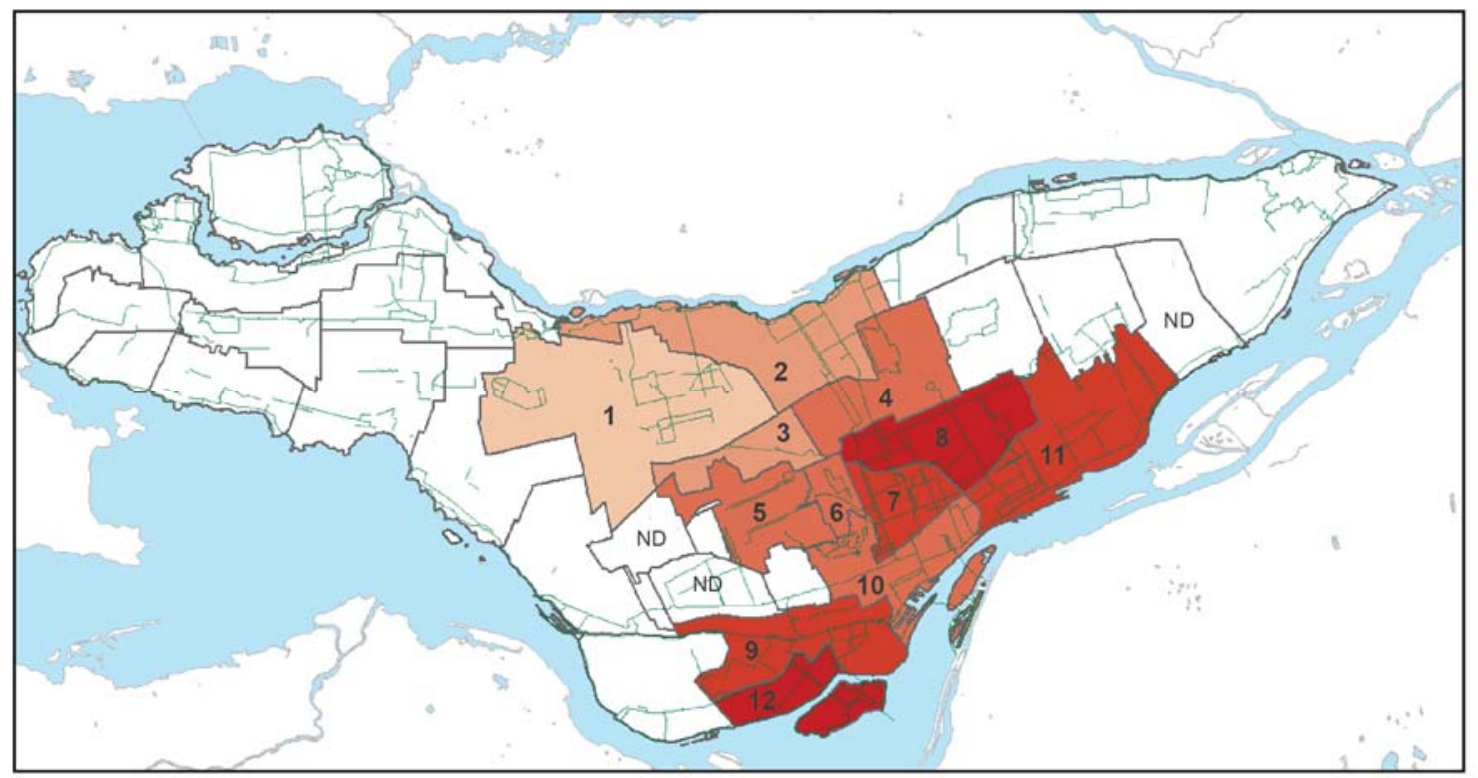

1. Saint-Laurent 2. Ahuntsic-Cartierville 3.Mont-Royal 4. Villeray-Saint-Michel-Parc-Extension 5.CDN-NDG 6.Outremont 7.Plateau-Mont-Royal 8. Rosemont-La Petite-Patrie 9. Sud-Ouest 10. Ville-Marie 11. Mercier-Hochelaga-Maisonneuve 12. Verdun

$$
\text { Bicycle facilities }
$$

Boroughs

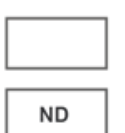

Less than 20 observations

No observations
Percentage of connected routes

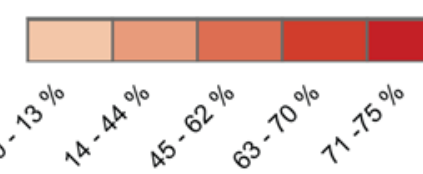

$\wedge$

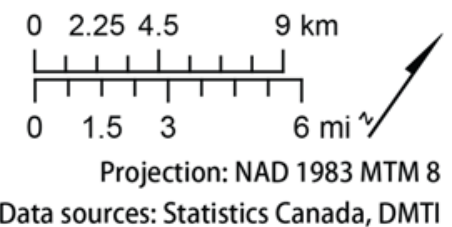

Data sources: Statistics Canada, DMTI

Figure 6: Spatial representation of the connectivity of the boroughs, based on origins of trips

\section{DISCUSSION AND CONCLUSION}

This paper develops a new methodology to assess bicycle network performance building on a set of complementary indicators developed based on reported behavior. The methodology is then applied to the Montreal 2013 bicycle network and OD data as a proof of concept. Observing cyclists' use of cycling facilities in reported bicycle trips, a cost reduction coefficient for bicycle facilities is derived (0.77). Considering that cyclists could have taken a more direct route if they had not taken the cycling facility, each kilometer travelled on the facility is perceived to be the equivalent of travelling 770 meters. Distances on streets are thus perceived to be 1.30 times more costly that distance on bicycle facilities by the average cyclist. 
Using this preference for facilities, we generated 1482 bicycle routes based on origins and destinations of cyclist trips from the 2013 survey and compared them to routes on a network with no preference for cycling facilities. For each route, two indicators reflecting a major attribute of a good bicycle route according to cyclists' preferences are generated: proportion of route on bicycle facilities and route diversion from the shortest path expressed as a proportion of the total trip. Aggregating these indicators at the borough level, we observe a clear trade-off between route directness and proportion of route along bicycle facilities: boroughs with a high average proportion of route on facilities also exhibit a relatively high diversion rates. These two indicators are accordingly assessed simultaneously, using a connectivity measure that identifies cycling routes with at least $50 \%$ of on a bicycle facility and a diversion of less than $12 \%$. The results show the discrepancies in terms of connectivity between the boroughs, and highlight that overall, the Montreal bicycle network does not provide a good connectivity with respect to observed origins and destinations of cyclists. It furthermore identifies boroughs that underperform relatively to the rest of the region, and provides recommendations on how to improve the connectivity of these boroughs by developing well-connected facilities with other boroughs. Since the methodology involves context-specific considerations, the results are not comparable across metropolitan regions. Yet, the methodology presented here can be replicated elsewhere to assess bicycle network performances spatially or over time, or to evaluate the impact of different projects. It is also important to note, however, that the methodology presented here should be further developed and tested in different contexts to address the limitations of the current study.

Nonetheless, from a transportation planning standpoint, the study provides a first step towards the development of an applicable method for spatially assessing bicycle network improvements beyond added kilometers. First, the study provides a simple method to generate bicycle routes that reflect the average cyclist's behavior by assigning a preference for bicycle facilities when a detour is required. As no clear guidance on assigning a preference value to cycling facilities exists, we provide a reasoning and derive a coefficient from observed cycling behavior that can be easily applied to an ArcGIS road and cycling network. While the level of preference for bicycle facilities may not be the same in all cities and for all types 
of facilities, this study demonstrates that it can be derived from reported or observed behavior, rather than using arbitrary values or stated preferences.

It is important to note here that the results presented in this study reflect the preferences and behavior of the 2009 sample of cyclists using bicycle paths. Yet, research has shown that travel behavior and perceptions vary according to socio-demographic characteristics as well as personal preferences (Aldred \& Dales, 2017; Aldred, Elliott, Woodcock, \& Goodman, 2017; Damant-Sirois et al., 2014; Hunt \& Abraham, 2007). As it is often the case with cycling surveys, our sample is predominantly composed of young male cyclists (median age of 31 years-old, $58 \%$ of men), which are typically more confident and less concerned with the presence of bicycle facilities (Dill \& McNeil, 2013; Geller, 2006). Conversely, women and older adults show a greater preference for and use of segregated bicycle lanes (Aldred \& Dales, 2017; Aldred et al., 2017; Tilahun et al., 2007). This has several equity implications as our results probably overestimate the connectivity of the network for women and for older individuals, and more generally for individuals having higher preferences for bicycle facilities. Furthermore, this study does not account for the heterogeneity in preferences and travel behavior as one single averaged coefficient is used, nor does it consider the preferences of non-cyclists. It should be noted, however, that the methodology presented in this study can be expanded to incorporate such considerations. With a reasonable sample size, cost reduction coefficients could be derived for different groups of the population to subsequently perform a segmented performance assessment. Moreover, whereas this study focuses on work/school trips, specific coefficients could be developed for a variety of destinations (e.g.: leisure destinations, healthcare services) to capture different needs and behavior. Further studies could also build on this methodology to model the cost coefficient as a function of socio-demographic and behavioral variables, in order to be able to subsequently apply it to the general population, as done in a recent study assessing the physical capability to travel by bicycle (Philips, Watling, \& Timms, 2018). The choice of the thresholds also entails equity implications. Whereas the average values were selected as benchmarks, this may not be representative of the more vulnerable or concerned users, which would require lower thresholds. As illustrated in this study, different thresholds can be used to assess the performance of the network and thereby better address the variable 
needs and preferences of users and potential users.

Second, this research suggests indicators that are easy to generate, interpret and communicate, and that have been shown to impact bicycle use and cyclists' experience (Pucher et al., 2011; Sener et al., 2009; Snizek et al., 2013). Ideally, a good connected cycling network should be the one where $100 \%$ of the cyclists can reach their desired destinations with a minimum diversion to use a bicycle facility and where they spend a significant amount of their trip on cycling facilities. Also, as shown in this study, performance indicators can be used to implement spatial analysis and identify areas that are most in need of improvements. While this study focused on diversion from shortest path and proportion of route travelled on bicycle facilities to develop a connectivity indicator, other indicators can be developed and included in the connectivity calculations to account for more factors influencing route choices. Such factors include achievable travel speed, slope and frequency and type of intersections (Broach et al., 2012; Ehrgott et al., 2012; Flügel et al., 2015). The performance indicators developed in this study can be generated by planners and researchers to assess different improvement scenarios, as done by Mekuria et al. (2012). Furthermore, as highlighted in a recent review of the literature on bicycle networks and bicycle use (Buehler \& Dill, 2016), more efforts are needed to assess the relationship between cycling level and the overall quality of the network. Further research could, therefore, investigate the extent to which the connectivity indicator developed in this study, which is accessible to most cities, relates to travel behavior.

The indicators presented in this study differ from previous methods in several ways. While LTS and BLOS have the advantage of including a greater number of attributes that influence cyclists' perceptions and behaviors, both methods require a large amount of data from a variety of data sources. As highlighted in previous research (Lowry et al., 2012; Wang et al., 2016), the complete data for BLOS is typically not available for a whole metropolitan region. While LTS is less data-intensive, it still requires a significant amount of data as well as on-site data collection (Mekuria et al., 2012), which makes it difficult to implement. Moreover, both approaches are based on national guidelines, which raises questions about their transferability to different contexts. In comparison, the method proposed in our study can be replicated by most planning or transport departments and can be adapted to the specific context through the use of a 
local travel survey, which is commonly available in metropolitan regions. As GPS tracking data is increasingly available, the method here can be used to better capture the influence of different attributes on travel behavior and subsequently derive context-specific performance measures. Also, since it is based on reported behavior of individuals, it lends itself to segmented analyses for specific population groups.

Finally, this study provides insight on the relevance of assessing bicycle network performance connectivity, which goes beyond the simple length of bicycle facilities in a city. While the length of the network provides a good indication of bicycle facilities supply, it does not account for desired trips and for efficient resource allocation. While most planning documents provide quantitative objectives in terms of added length, connectivity is increasingly seen as an objective for cycling network development, as it is the case in Montreal (Ville de Montréal, 2008, 2013b). Accordingly, the development of quantitative connectivity measures becomes increasingly relevant for practitioners and should be included in transport plans as key performance measures. Moreover, assessing the performance of bicycle network connectivity offers insight into the impacts of planning bicycle infrastructure at the borough level. In Montreal, while the vision for transportation networks is determined at the agglomeration level, boroughs and independent municipalities are responsible for implementing bicycle lanes, perhaps contributing to the poor connectivity revealed in this study. 


\section{ACKNOWLEDGMENT}

The authors would like to thank Gabriel Damant-Sirois and Jacob Larsen for their work on a previous cycling survey in Montreal. Additionally, thanks to David Verbich for his critical comments on the paper.

We also want to thank two anonymous reviewers for their constructive feedback on the manuscript. Finally, we gratefully acknowledge the financial support received from the Natural Sciences and Engineering Research Council of Canada (NSERC) and the Fonds de recherche du Québec-Nature et technologies (FRQNT).

\section{REFERENCES}

Agence Métropolitaine de Montréal (AMT). (2013). 2013 Origin-Destination Survey.

Aldred, R., \& Dales, J. (2017). Diversifying and normalising cycling in London, UK: An exploratory study on the influence of infrastructure. Journal of Transport \& Health, 4, 348-362. doi:10.1016/j.jth.2016.11.002

Aldred, R., Elliott, B., Woodcock, J., \& Goodman, A. (2017). Cycling provision separated from motor traffic: a systematic review exploring whether stated preferences vary by gender and age. Transport Reviews, 37(1), 29-55. doi:10.1080/01441647.2016.1200156

Aultman-Haulm, L., Hall, F., \& Baetz, B. (1997). Analysis of bicycle commuter routes using geographic information systems: Implications for bicycle planning Transportation Research Record(1578), 102-110.

Babin, T. (2015, June 22). 5 things to learn from North America's (second) most bike-friendly city. Calgary Herald.

Broach, J., Dill, J., \& Gliebe, J. (2012). Where do cyclists ride? A route choice model developed with revealed preference GPS data. Transportation Research Part A: Policy and Practice, 46(10), 1730-1740.

Buehler, R., \& Dill, J. (2016). Bikeway networks: A review of effects on cycling. Transport Reviews, 36(1), 9-27.

Buehler, R., \& Pucher, J. (2012). Cycling to work in 90 large American cities: New evidence on the role of bike paths and lanes. Transportation, 39(2), 409-432. doi:10.1007/s11116-011-9355-8

Casello, J., \& Usyukov, V. (2014). Modeling cyclists' route choice based on GPS data. Transportation Research Record: Journal of the Transportation Research Board(2430), 155-161. doi:10.3141/2430-16

Copenhagenize Design Company. (2015). The 2015 Copenhagenize Index. Bicycle-friendly cities. Retrieved from http://copenhagenize.eu/index/

Damant-Sirois, G., Grimsrud, M., \& El-Geneidy, A. (2014). What's youre type: A multidimensional cyclist typology. Transportation, 41(6), 1153-1169.

Dill, J. (2009). Bicycling for transportation and health: The role of infrastructure. Journal of public health policy, 30(1), S95-S110. doi:10.1057/jphp.2008.56

Dill, J., \& McNeil, N. (2013). Four types of cyclists? Examination of typology for better understanding of bicycling behavior and potential. Transportation Research Record: Journal of the Transportation Research Board(2387), 129-138.

Ehrgott, M., Wang, J., Raith, A., \& van Houtte, C. (2012). A bi-objective cyclist route choice model. Transportation Research Part A: Policy and Practice, 46(4), 652-663. doi:10.1016/j.tra.2011.11.015 
Flügel, S., Ramjerdi, F., Veisten, K., Killi, M., \& Elvik, R. (2015). Valuation of cycling facilities with and without controlling for casualty risk. International Journal of Sustainable Transportation, 9(5), 364-376. doi:10.1080/15568318.2013.798749

Geller, R. (2006). Four types of cyclists. Retrieved from Portland, OR, US: https://www.portlandoregon.gov/transportation/article/264746

Handy, S. L., \& Xing, Y. (2011). Factors correlated with bicycle commuting: A study in six small US cities. International Journal of Sustainable Transportation, 5(2), 91-110.

Houston-Galveston Area Council. (2016). Bridging Our Communities.

Hunt, J., \& Abraham, J. (2007). Influences on bicycle use. Transportation, 34(4), 453-470. doi:10.1007/s11116-006-9109-1

Larsen, J., \& El-Geneidy, A. (2011). A travel behavior analysis of urban cycling facilities in Montréal, Canada. Transportation Research Part D: Transport and Environment, 16(2), 172-177.

Lee, Y. (2008). Comparative measures for transit network performance analysis. Journal of the Transportation Research Forum, 47(3).

Lee, Y., Choi, J., Yu, J., \& Choi, K. (2015). Geographical applications of performance measures for transit network directness. Journal of Public Transportation, 18(2), 89-110. doi:10.5038/2375-0901.18.2.7

Levinson, D., \& El-Geneidy, A. (2009). The minimum circuity frontier and the journey to work. Regional Science and Urban Economics, 39(6), 732-738. doi:10.1016/j.regsciurbeco.2009.07.003

Lowry, M., Callister, D., Gresham, M., \& Moore, B. (2012). Assessment of communitywide bikeability with bicycle level of service. Transportation Research Record: Journal of the Transportation Research Board(2314), 41-48. doi:10.3141/2314-06

Mekuria, M., Furth, P., \& Nixon, H. (2012). Low-stress bicycling and network connectivity. Retrieved from San José: Mineta Transportation Institute: http://scholarworks.sjsu.edu/mti publications/74/

Mullen, C., Tight, M., Whiteing, A., \& Jopson, A. (2014). Knowing their place on the roads: What would equality mean for walking and cycling? Transportation Research Part A: Policy and Practice, 61, 238-248.

Pereira, R., Schwanen, T., \& Banister, D. (2016). Distributive justice and equity in transportation. Transport Reviews.

Philips, I., Watling, D., \& Timms, P. (2018). Estimating individual physical capability (IPC) to make journeys by bicycle. International Journal of Sustainable Transportation, 12(5), 324-340. doi:10.1080/15568318.2017.1368748

Pucher, J., \& Buehler, R. (2017). Cycling towards a more sustainable transport future. Transport Reviews, $37(6)$.

Pucher, J., Buehler, R., \& Seinen, M. (2011). Bicycling renaissance in North America? An update and re-appraisal of cycling trends and policies. Transportation Research Part A: Policy and Practice, 45(6), 451-475. doi:10.1016/j.tra.2011.03.001

Pucher, J., Dill, J., \& Handy, S. (2010). Infrastructure, programs, and policies to increase bicycling: An international review. Preventive Medicine, 50, Supplement, S106-S125. doi:10.1016/j.ypmed.2009.07.028

Rietveld, P., \& Daniel, V. (2004). Determinants of bicycle use: do municipal policies matter? Transportation Research Part A: Policy and Practice, 38(7), 531-550.

Schoner, J., \& Levinson, D. (2014). The missing link: Bicycle infrastructure networks and ridership in 74 US cities. Transportation, 41(6), 1187-1204. doi:10.1007/s11116-014-9538-1

Sener, I., Eluru, N., \& Bhat, C. (2009). An analysis of bicycle route choice preferences in Texas, US. Transportation, 36(5), 511-539. doi:10.1007/s11116-009-9201-4

Snizek, B., Nielsen, T., \& Skov-Petersen, H. (2013). Mapping bicyclists' experiences in Copenhagen. Journal of Transport Geography, 30, 227-233. doi:10.1016/j.jtrangeo.2013.02.001

Tilahun, N., Levinson, D., \& Krizek, K. (2007). Trail, lanes, or traffic: Valuing bicycle facilities with an adaptive stated preference survey. Transportation Research Part A: Policy and Practice, 41(4), 287-301. doi:10.1016/j.tra.2006.09.007 
Vélo-Québec. (2015). L'État du vélo à Montréal en 2015. Retrieved from Montréal: http://ville.montreal.qc.ca/pls/portal/docs/page/transports_fr/media/documents/etat_velo_2015.pd $\underline{f}$

Vijayakumar, N., \& Burda, C. (2015). Cycle Cities: Supporting cycling in Canadian cities. Retrieved from Calgary, Canada: https://www.pembina.org/reports/cycle-cities-full-report.pdf

Ville de Montréal. (2008). Montreal Transportation Plan. Retrieved from http://ville.montreal.qc.ca/pls/portal/docs/PAGE/TRANSPORT_V2_EN/MEDIA/DOCUMENTS transportation_plan_2008.pdf

Ville de Montréal. (2011). Population totale et superficie des arrondissements de Montréal et des villes liées, Agglomération de Montréal. Retrieved from http://ville.montreal.qc.ca/pls/portal/docs/PAGE/MTL_STATS_FR/MEDIA/DOCUMENTS/POP ULATION\%20ET\%20SUPERFICIE\%202011.PDF

Ville de Montréal. (2013a). Carte du réseau cyclable. Retrieved from http://donnees.ville.montreal.qc.ca/dataset/pistes-cyclables

Ville de Montréal. (2013b). Demain Montréal: Projet de plan de développement de Montréal. Retrieved from

http://ville.montreal.qc.ca/pls/portal/docs/page/planifier_mtl_fr/media/documents/pdm_demain $\underline{\text { montreal.pdf }}$

Ville de Montréal. (2015). Montréal en statistiques. Retrieved from http://ville.montreal.qc.ca/portal/page?_pageid $=6897,67633583 \&$ dad $=$ portal\&_schema $=$ PORTA $\mathrm{L}$

Walker, P. (2014, October 8). World's best cycling cities. CNN.

Wang, H., Palm, M., Chen, C., Vogt, R., \& Wang, Y. (2016). Does bicycle network level of traffic stress (LTS) explain bicycle travel behavior? Mixed results from an Oregon case study. Journal of Transport Geography, 57, 8-18.

Willis, D. P., Manaugh, K., \& El-Geneidy, A. (2015). Cycling under influence: summarizing the influence of perceptions, attitudes, habits, and social environments on cycling for transportation. International Journal of Sustainable Transportation, 9(8), 565-579. doi:10.1080/15568318.2013.827285

Winters, M., Teschke, K., Grant, M., Setton, E., \& Brauer, M. (2010). How far out of the way will we travel? Built environment influences on route selection for bicycle and car travel. Transportation Research Record: Journal of the Transportation Research Board(2190), 1-10. 